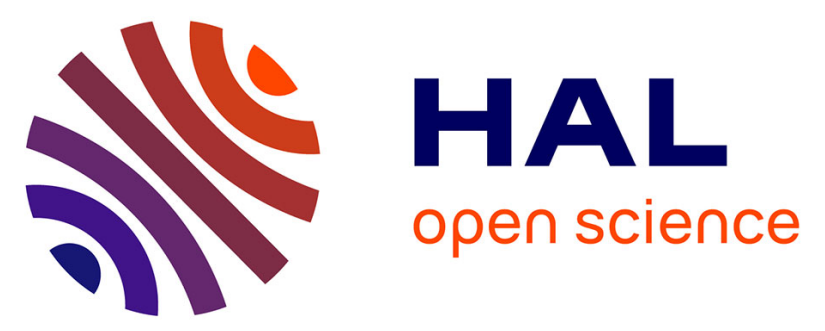

\title{
Sexual isolation with and without ecological isolation in marine isopods Jaera albifrons and $\mathrm{J}$. praehirsuta
}

Ambre Ribardière, Elsa Pabion, Jérôme Coudret, Claire Daguin-Thiébaut, Céline Houbin, Stéphane Loisel, Sébastien Henry, Thomas Broquet

\section{To cite this version:}

Ambre Ribardière, Elsa Pabion, Jérôme Coudret, Claire Daguin-Thiébaut, Céline Houbin, et al.. Sexual isolation with and without ecological isolation in marine isopods Jaera albifrons and J. praehirsuta. Journal of Evolutionary Biology, In press, 10.1111/jeb.13559 . hal-02349248

\section{HAL Id: hal-02349248 \\ https://hal.sorbonne-universite.fr/hal-02349248}

Submitted on 5 Nov 2019

HAL is a multi-disciplinary open access archive for the deposit and dissemination of scientific research documents, whether they are published or not. The documents may come from teaching and research institutions in France or abroad, or from public or private research centers.
L'archive ouverte pluridisciplinaire HAL, est destinée au dépôt et à la diffusion de documents scientifiques de niveau recherche, publiés ou non, émanant des établissements d'enseignement et de recherche français ou étrangers, des laboratoires publics ou privés. 
Sexual isolation with and without ecological isolation in marine isopods Jaera albifrons and J. praehirsuta.

Ambre Ribardière ${ }^{1}$, Elsa Pabion ${ }^{1}$, Jérôme Coudret ${ }^{1}$, Claire Daguin-Thiébaut ${ }^{1}$, Céline Houbin ${ }^{1,2}$,

5 Stéphane Loisel ${ }^{1}$, Sébastien Henry ${ }^{1,2}$, Thomas Broquet $^{1}$

1- CNRS \& Sorbonne Université, UMR 7144, Station Biologique de Roscoff, 29680 Roscoff, France.

2- CNRS \& Sorbonne Université, FR2424, Station Biologique de Roscoff, 29680 Roscoff, France.

Corresponding author: Thomas Broquet, Station Biologique de Roscoff, 29680 Roscoff, France. Email: thomas.broquet@sb-roscoff.fr, phone number+33298292351 


\section{Abstract}

Sexual barriers associated with mate choice are often found to be associated with some level of ecological isolation between species. The independence and relative strength of sexual isolation are thus difficult to assess. Here we take advantage of a pair of marine isopod species (Jaera albifrons and J. praehirsuta) that show sexual isolation and coexist in populations where they share the same microhabitat or not (i.e. without or with ecological isolation). We estimated the strength of sexual isolation between J. albifrons and J. praehirsuta using no-choice trials and a multiple-choice experimental population. We found that sexual isolation is strong in both the presence and absence of ecological isolation, but that it is asymmetric and fails to prevent interspecific gene flow entirely.

25 First-generation intrinsic post-zygotic barriers were low, and there was no sexual isolation within J. praehirsuta across habitats. The J. albifrons / J. praehirsuta species pair thus provides an example where the role of sexual isolation as a barrier to gene flow i) does not depend upon current ecological isolation, ii) seems to have evolved independently of local ecological conditions, but iii) is insufficient to complete speciation entirely on its own. 
Sexual isolation resulting from divergence in mating choice is common between closely related animal species, and the evolution of this type of barrier is considered to be a major component of speciation (Coyne \& Orr, 2004). However, sexual barrier effects are often found in conjunction with some level of ecological isolation, raising the following questions (discussed e.g. in Ritchie, 2007; Maan \& Seehausen, 2011): What are the current relative contributions of sexual and ecological barrier effects in reproductive isolation between animal species? How often, if ever, has sexual isolation initiated speciation rather than evolving secondarily to ecological isolation? And may sexual isolation be an independent driver of speciation or is the evolution of sexual barriers necessarily linked with that of ecological isolation? Similar questions extend to other isolating barriers as well, but we focus here on the relationship between sexual and ecological isolation, and more precisely on the last question, pertaining to the interdependence of these two isolating barriers.

Sexual isolation may be tightly linked with ecological isolation for several reasons (see Butlin \& Smadja, 2018 for a discussion of coupling mechanisms and their importance in speciation). A direct form of coupling happens when some genes or traits affect ecological and sexual barriers at once

45 (reviewed in Servedio et al., 2011). In Heliconius butterflies, for example, wing colour patterns affect both mimicry and mating signals, resulting in a strong combination of ecological and sexual barrier effects (Jiggins et al., 2001). Along the same line, sexual and ecological barriers will coevolve when they involve overlapping metabolism networks, or sets of genes that are physically linked on the genome.

Furthermore, when there is no such intrinsic interdependence between barrier effects, other forms of coupling can happen if environmental conditions promote ecological isolation and simultaneously affect sexual isolation mechanisms. Such situations occur when the environment has an effect on male phenotypes, mortality costs associated with sexual display or choosiness, or the transmission of sexual signals (e.g host-dependent sexual signalling in Enchenopa treehoppers

55 McNett \& Cocroft, 2008). All these cases may lead to the simultaneous evolution of sexual and 
ecological isolation (reviewed in Maan \& Seehausen, 2011; Nosil, 2012; Safran et al., 2013;

Boughman \& Svanback, 2017; Servedio \& Boughman, 2017). This list should even be extended if one considers not only the behavioural aspects of sexual isolation but also gametic isolation. The impact of ecological differentiation appears ubiquitous and one may wonder in what conditions can sexual isolation evolve independently from ecological isolation.

Sexual selection mechanisms such as the Fisher-Lande process of coevolution between arbitrary male traits and female preferences can theoretically drive reproductive isolation largely independently of environmental heterogeneity and ecological barrier effects. This is also perhaps possible in some cases when good genes or compatible genes systems drive sexual isolation between populations. An objective of empirical research is thus to explore how sexual isolation mechanisms are connected to ecological conditions and preferences, and evaluate to what extent sexual isolation may act as an independent driving force in speciation.

Hybrid zones provide good opportunities to investigate the interplay between different types of isolating barriers, and the most detailed information should come from situations where one can investigate the role of sexual isolation in different ecological contexts. This is possible in mosaic or otherwise replicated hybrid zones (reviewed in Harrison \& Larson, 2016) where hybridizing taxa meet repeatedly in different locations. In such cases, when sexual isolation was proven to be a critical barrier to gene flow it appeared to be nonetheless strongly dependent upon ecological conditions. This is either because sexual and ecological isolation involved the same traits, or sexual isolation mechanisms were linked with ecological conditions. Habitat heterogeneity may then have driven ecological isolation and sexual isolation simultaneously (e.g. speciation in Gasterosteus sticklebacks and Pundamilia cichlids driven by adaptation of female perceptual sensitivity to ambient light combined with sexual selection on male colour, Boughman, 2001; 2002; Seehausen et al., 2008). In these examples, sexual isolation is likely to break down when ecological conditions are homogenized 80 (Seehausen, 2009, see also Taylor et al., 2006). There are also many other cases of mosaic or replicated hybrid zones where sexual isolation is not fully understood but where ecological isolation 
or spatial segregation, regardless of other isolating barriers, appeared fundamental to the maintenance of reproductive isolation (e.g. field crickets, Harrison \& Rand, 1989; marine mussels, Bierne et al., 2003; swordtail fish, Culumber et al., 2011; river herrings, Hasselman et al., 2014; lampreys, Rougemont et al., 2015).

There are comparatively few cases of replicated hybrid zones where sexual isolation appears to be strong and essentially independent of ecological isolation. A potential example is the hybrid zone between Chorthippus grasshoppers in northern Spain, where female mate choice based on male calling songs generates strong premating isolation that seems independent from ecological

90 differentiation, at least in some populations (Bridle et al., 2001; Bridle et al., 2002; Bridle et al., 2006; but see Bailey et al., 2012). Other examples come from situations where sexual isolation is reinforced by selection against hybridization. For instance, the hybrid zone between Mus musculus musculus and $M . m$. domesticus subspecies of the house mouse have been studied repeatedly in distant regions, confirming the role of sexual isolation regardless of geographic and ecological conditions 95 (Smadja et al., 2004; Smadja \& Ganem, 2005; Bimova et al., 2011).

When sexual isolation is found in conjunction with ecological isolation, it is interesting to understand the relative roles and interdependence between these two types of barriers. It informs us on the mechanisms that are currently shaping species boundaries, and in some cases on the origin and evolution of these mechanisms (Boughman, 2001; Jiggins et al., 2001; Seehausen et al., 2008). Here we focus on isopods Jaera albifrons and J. praehirsuta, two closely related species that show strong sexual isolation and generally occupy distinct habitats but can also be found in a region where they coexist in the same habitat, therefore allowing us to ask whether sexual isolation persists in a situation where ecological isolation does not.

The two species J. albifrons and J. praehirsuta belong to the Jaera albifrons complex. This 105 complex is composed by five species of small $(2-5 \mathrm{~mm})$ marine isopods that live on the shores of the temperate and cold waters on both sides of the North-Atlantic Ocean (Bocquet, 1953; Solignac, 1978). All species of the complex are phenotypically indistinguishable except for male secondary 
sexual traits that are used for tactile courtship (Bocquet, 1953; Solignac, 1981). The males of each species have specific sets of setae and spines located at different places on their peraeopods (Fig. 1)

110 and they use these features to brush a particular region of the back of females to get them to engage in sexual intercourse. The males of both species share the same basic courtship behaviour, whereby they mount females in a head-to-tail position and exercise their brushes. Females accept or reject a male based on this tactile stimulus, and behavioural isolation is thought to ensure a nearly complete arrest of interspecific gene flow in nature (Solignac, 1978).

Sexual isolation is thus currently a very important barrier between these species, and it could have initiated speciation (Solignac, 1981). However, the five species of the complex also show some level of habitat segregation on the seashore. The marine intertidal zone is an interesting environment to study ecological isolation as it presents contrasted ecological conditions at a small spatial scale. The distribution of species composing the Jaera albifrons complex was found to vary 120 with intertidal zonation, exposure, salinity, and substrate (Naylor \& Haahtela, 1966; Jones, 1972). Most remarkably, while J. albifrons and J. praehirsuta occupy the same narrow belt of intertidal habitats along the American and European shores of the North-Atlantic Ocean, J. albifrons is primarily found under pebbles and stones while J. praehirsuta is primarily found on intertidal brown algae (at least along European coasts, Bocquet, 1953; Naylor \& Haahtela, 1966; Naylor \& Haahtela,

125 1967). These habitats are often in immediate proximity, and these preferences are not strict (Solignac, 1981; Ribardière et al., 2017), but they still imply that ecological isolation is strong and thus its current relative contribution to total reproductive isolation must be important (because this is the first barrier to occur in the life-cycle, see Coyne \& Orr, 2004 p. 58).

The J. albifrons / J. praehirsuta pair gives us an opportunity to examine the relative strength

130 and interdependence of sexual isolation and ecological isolation because these two species that usually use distinct habitats were reported to exceptionally coexist in a population where they share the same habitat (under stones, that is, the primary J. albifrons habitat, Solignac, 1969b; a). This coexistence of the two species in a unique habitat was recently found to have persisted for decades 
and to be more widespread than previously thought as it extends to several other sites at least in the

135 French region Normandy and in the United Kingdom (Ribardière et al., 2017; see also Mifsud 2011). Hybridization happens in these populations (Solignac, 1969a) and results in various levels of introgression (Ribardière, 2017; Ribardière et al., 2017), pointing toward reduced reproductive isolation. Interestingly however, in these hybridizing populations most males bear sexual traits that are clearly identified as belonging to one or the other species and intermediate phenotypes are scarce, suggesting that reproductive isolation does not break down completely.

Ribardière et al. (2017) suggested that sexual isolation is one of the components allowing the persistence of bimodality in spite of introgressive hybridization. If this hypothesis is correct and sexual isolation does not disappear in absence of ecological isolation, then it would suggest that sexual isolation has evolved without a direct dependence on ecological conditions and ecological 145 isolation.

Our main objective was to test whether sexual isolation persists in spite of introgressive hybridization in populations showing no ecological isolation. To reach this objective we quantified sexual isolation between J. albifrons and J. praehirsuta using experimental "no-choice" crosses between individuals that originated either from a region where ecological isolation is strong or a region where ecological isolation is lacking and the two taxa hybridize. Using individuals from this second region we also quantified sexual isolation in a multiple-choice experimental population where females can escape males and there is competition between individuals, unlike in no-choice crosses where mate rejection may be more constrained (e.g. Jiggins et al., 2001).

In addition, no-choice crosses were also performed with individuals from across our two

155 regions in order to test whether sexual isolation could have evolved differently in different ecological contexts. In particular, species J. praehirsuta is found on markedly distinct shore substrates (seaweeds vs pebbles) in our two study areas, giving us the opportunity to test for an effect of this ecological difference on sexual isolation between populations within a unique species.

Finally, we took advantage of our experimental crosses to check for potential first-generation 
160 intrinsic post-zygotic barrier effects. While such isolating barriers are more likely to operate at later generations, chromosomal differences have been reported in our two focal species (Staiger \& Bocquet, 1956; Lécher \& Prunus, 1971). Thus, we took the opportunity of our experiments to check for the possibility that such differences have an effect in first-generation hybrids. 


\section{Methods}

165 Species

Contrary to males, females of the five species within the Jaera albifrons complex are morphologically indistinguishable (Bocquet, 1953; but see Khaitov et al., 2007 for a discussion of potential phenotypic differences). Females follow the same reproductive cycle (total duration ca. 3 weeks) during which embryos develop in a marsupium (brood pouch) for about 12 days (Solignac,

170 1976). Development is direct, meaning that the dispersal capacity of Jaera species is certainly much more limited than that of other marine invertebrates with a pelagic larval phase. Offspring measure ca. $0.5 \mathrm{~mm}$ when they are released from the marsupium. Individuals become sexually mature and can be sexed within 4 to 5 weeks based on praeoperculum differentiation (e.g. Solignac, 1979).

\section{Experimental set-up}

Our study is based on the analysis of the reproductive output of virgin males and females used in intra- and inter-specific controlled mating experiments (set-up detailed in Fig. 2). In theory, whether or not juveniles are produced in these experiments could result not only from sexual barrier effects but also post-mating pre-zygotic or intrinsic post-zygotic barrier effects (e.g. inviability of hybrid embryos). However, all past analyses of inter-specific crosses in the Jaera albifrons complex have shown that females either rejected hetero-specific males or produced a normal number of offspring. That is, females that produced no offspring did not mate (e.g. Solignac, 1978 p. 49), and females mated by a heterospecific male did not show any reduction in fecundity (e.g. Solignac, 1978 pp. 80-82). There is no postmating copulatory behavioural isolation or mechanical isolation (Bocquet, 1953 p. 297; Jones \& Fordy, 1971; Veuille, 1978). The complete absence of offspring produced by a pair of individuals is thus a good indicator for sexual isolation (and most probably the behavioural component of sexual isolation, although gametic isolation has yet to be investigated in this group, see discussion). 
To obtain virgin individuals of both sexes and both species, we first sampled (unidentified)

190 females in natural populations where Jaera albifrons and J. praehirsuta coexist (Fig. 2). We chose populations where we knew from previous work (Solignac, 1978; Ribardière, 2017; Ribardière et al., 2017) that the two species live on different substrates (pebbles vs seaweeds, populations from Brittany) or share the same substrate (pebbles, populations from Normandy). Then we individually reared in the lab the offspring produced by these females (which were fertilized by unknown males in nature prior to sampling) until they could be sexed and males could be identified. Females were sorted as J. albifrons or J. praehirsuta according to the sexual traits held by their brothers. At this stage we thus had a series of J. albifrons and J. praehirsuta virgin adults originating from populations with or without ecological isolation (region "Brittany" vs region "Normandy"). These individuals could then be used in the controlled experiments described below. Female sampling and experimental conditions are detailed in supplementary information.

\section{No-choice crosses within each region}

In order to understand reproductive isolation processes with or without ecological isolation, we first ran a series of crosses where one male and one female from the same region were paired and their reproductive output monitored. These crosses featured intraspecific and interspecific crosses using either a pair of individuals from Brittany (where ecological isolation is strong) or a pair from Normandy (where there is no ecological isolation).

We monitored 23 intraspecific and 17 interspecific crosses within each of these two conditions (that is, 40 crosses within each region of origin; details in Table 1). These numbers were somewhat

210 constrained for three reasons. First, the number of individuals available for the experiment depended on the (unknown) species identity of the females sampled in the wild, their survival and fecundity in the lab, and the survival of their offspring (see preliminary steps in Fig. 2). Second, and more importantly, crosses were designed so that the male and the female that were paired never 
shared the same mother. Third, each individual was used in a unique cross, so that each cross was an

215 independent replicate.

For each cross we recorded i) if it successfully produced offspring, ii) how long it took for the first offspring to appear, iii) how many offspring were contained in each brood produced, and iv) offspring survival at 35 days. These data were used to estimate reproductive isolation components as described below. All analyses were performed in R v.3.3.3 (R Core Team, 2017).

Reproductive isolation estimated from no-choice crosses within each region

Ecological, sexual, and first-generation intrinsic post-zygotic components of reproductive isolation were quantified following Sobel and Chen (2014) using estimators that vary between -1 (complete disassortative mating, probability of interspecific gene flow $=1$ ) to 1 (complete

225 reproductive isolation, probability of interspecific gene flow $=0$ ). To compare reproductive isolation components in the presence vs absence of ecological isolation, all the computations described below were performed independently using crosses featuring individuals "from Brittany" on one hand, and "from Normandy" on the other hand (that is, two independent sets of analyses).

First, because J. albifrons and J. praehirsuta in Brittany do not have strictly non-overlapping habitats, we used survey data from Ribardière et al. (2017) in the same study areas to quantify ecological isolation as

$$
R I_{\text {eco }}=1-(S /(S+U))
$$

where $U$ was the proportion of individuals found on the primary habitat of their species and $S$ was the proportion of individuals found on the alternative habitat (i.e. $S$ is the probability that an 235 individual is in a place where it will meet the other species, that is, "shared"). This equation gives an estimate of the reduction in interspecific gene flow that would happen if individuals would mate randomly within each habitat (i.e. ecological isolation only). 
Second, we estimated three components of sexual and intrinsic post-zygotic isolation (listed in Table 2) from our experimental crosses. The strength of each reproductive isolation barrier $i$ was estimated as

$$
R I_{i}=1-2 \times\left(H_{i} /\left(H_{i}+C_{i}\right)\right)
$$

where $H_{i}$ and $C_{i}$ refer to variables calculated for heterospecific and conspecific pairs (Sobel \& Chen, 2014). For sexual isolation $\left(R I_{1}\right), H$ and $C$ were the proportions of inter- and intraspecific crosses that successfully produced offspring. For components of post-zygotic isolation, $H$ and $C$ referred to brood size (number of offspring) or survival (proportion of offspring surviving at day 35) observed from intra- and interspecific crosses (see column "parameter" in Table 2). Each of these components of reproductive isolation was thus estimated independently, giving the strength $R I_{i}$ that each barrier would have if it were acting alone. Note that $R I_{1}, R I_{2}$, and $R I_{3}$ correspond here to different components of RI and should not be confused with similar notations in Sobel \& Chen, 2014.

250 A 95\% bootstrap confidence interval was calculated for each $R I$ estimate by resampling 10000 times the observed data if sample sizes where not too small (i.e. $S$ and $U$ or $H_{i}$ and $C_{i} \geq 14$, Table 2).

Total reproductive isolation was estimated using the product of $H_{i}$ and $C_{i}$ across all components of isolation (see details in supplementary information):

$$
R I_{\text {tot }}=1-2 \frac{S \times \prod_{i} H_{i}}{S \times \prod_{i} H_{i}+\prod_{i} C_{i}}
$$
effect of previously acting barriers as (Sobel \& Chen, 2014):

$$
A C_{i}=R I_{[1, i]}-R I_{[1, i-1]}
$$

With this definition, individual contributions $A C_{i}$ can be seen as additive components of $R I_{\text {tot }}$.

\section{No-choice crosses across regions}

In addition to the 80 crosses described so far, we ran another series of 80 intraspecific and interspecific crosses (Table 1) pairing individuals from opposite regions (and thus opposite habitats in the case of J. praehirsuta, which lives on algae in Brittany vs. under stones in Normandy). These 
crosses were useful to test for an effect of habitat on sexual isolation within and between species.

265 They also provided a direct test that J. albifrons (or J. praehirsuta) from across our two separate regions actually belong to the same biological species, an implicit assumption of this study and most previous investigations with this system (Solignac 1969b; Ribardière et al. 2017). The reproductive output of these crosses was recorded as described above for no choice crosses within each region.

Multiple-choice experiment

The general aim of the multiple-choice experiment (Fig. 2) was to estimate sexual isolation based on the reproductive output of males and females J. albifrons and J. praehirsuta freely interacting in an experimental population (and thus experiencing intra-sexual competition and easier male avoidance by females, unlike in no-choice experiments). This experiment focused only on the

275 situation where the two species occupy the same habitat in the wild and thus interact frequently. Hence we used virgin adult individuals obtained from the no-choice crosses described above (region Normandy only), so that we could mix J. albifrons, J. praehirsuta, and F1 hybrids all obtained in the same controlled conditions and all originating from a region without ecological isolation (Fig. 2).

We used 15 females of each species, 17 males of each species, and 17 males produced by 280 inter-specific crosses. We included F1 hybrid males (and more males than females altogether) in order to estimate sexual isolation in a situation where females would have free choice, by contrast with the no-choice design. These numbers were constrained by several parameters, including the fact that we avoided mixing related males and females (i.e. two males could be brothers, but we did not use males and females from within the same family). Moreover, 4 out of 17 "hybrid" males turned out to have resulted from a cross between a brother and sister J. praehirsuta prior to the experiment and were removed from all analyses (see details in results and supplementary information). All remaining F1 hybrid males came from male J. praehirsuta $\mathrm{x}$ female J. albifrons crosses. 
Here we outline the experimental set-up, which is presented in detail in supplementary

290 information. All adults were kept together in a small aquarium for 12 days. After that, all surviving females were removed from the aquarium and kept individually until they produced offspring, which were then reared individually. All adults were photographed before and after the experiment and genotyped at 13 microsatellite loci (Ribardière et al., 2015). All offspring were also genotyped at the same loci. Photo-identification and genetic parentage assignment (using software Colony v2.0.6.1, Jones \& Wang, 2010) were used to identify adult females after the experiment (remember that females of the two species cannot be distinguished otherwise) and identify the father of each offspring.

In addition, the secondary sexual traits of all adult males (Fig. 1) were examined under a microscope to determine their role in male mating success. This is useful in this experiment because multiple-choice conditions give access to variance in male mating success with females of the two species, and one can thus explore the link between male traits and sexual isolation. Male phenotypes were summarized using principal component analyses (PCA) based upon 14 phenotypic variables (see supplementary information). This approach produces linear combinations of traits that are more efficient for investigating sexual isolation than multiple trait variables separately (Hohenlohe \& Arnold, 2010). We used coordinates on the first PCA axis to assess whether female mate choice matched the distribution of male sexual traits within each species (building upon Ryan \& Rand, 1993; Arnold et al., 1996).

\section{Sexual isolation estimated from the multiple-choice experiment}

We aimed to compare sexual isolation in these multiple-choice settings with that measured in no-choice crosses. Hence in a first step we used the same theoretical framework (Sobel \& Chen, 2014) to estimate sexual isolation $R I_{1}$ following equation (2) with $H_{1}$ and $C_{1}$ defined as the proportions of inter-specific and intra-specific crosses that successfully produced offspring. These proportions were calculated as the number of successful pairs divided by the number of potential 
315 pairs that could possibly have formed. Note that because we initially introduced the same number of males of each species in the experiment, using proportions (as above) or absolute numbers of successful pairs (as in Sobel \& Chen, 2014) would lead to the same result for $R I_{1}$.

It turned out that sexual isolation was very strong: only one interspecific pair and two pairs involving F1 hybrid males produced offspring, while all other successful pairs were conspecific (see results). Hence downstream barriers involving brood size and survival were not quantified because they would be based on too few samples.

In a second step, sexual isolation was estimated using a framework described by Rolan-Alvarez and Caballero (2000) that applies to multiple-choice experiments. Rather than estimating the effect of sexual isolation on interspecific gene flow (as in Sobel and Chen's method), this estimation

325 procedure aims to isolate the effect of mate choice as a cause of reproductive isolation. The computation takes into account inequalities in mating frequencies rather than assuming that the two species have the same propensity to mate. In addition, it can detect asymmetries in sexual isolation. Note that this method can also be applied to no-choice data (Nosil et al., 2002; Coyne et al., 2005) if they are obtained from equal numbers of no-choice trials of each type (unlike in this study, see Table 330 1).

To estimate sexual isolation we counted the number of male/female pairs of each type (e.g. J. albifrons/J. albifrons, J. albifrons/J. praehirsuta, etc.) that successfully reproduced. Pair sexual isolation (PSI) was estimated for every pair type following Rolan-Alvarez and Caballero (2000). This method gives a conservative view of sexual isolation as it is defined for each pair type as the number of observed pairs divided by the number of expected pairs given the actual mating success observed. We then followed these authors' recommendation to estimate $I_{P S I}$, a modified joint isolation index (Merrell, 1950) based on PSI statistics and that varies from 0 (no isolation) to 1 (complete isolation). Details of the computation are described in Rolan-Alvarez and Caballero (2000) and Perez-Figueroa et al. (2005). Values of $P S I, I_{P S I}$, and their statistical significance were computed using JMating v1.0.8 


\section{Results}

\section{Reproductive isolation within each region}

Estimates of reproductive isolation are presented in Table 2. In region Brittany, Ribardière et al. (2017) reported $141 \mathrm{~J}$. albifrons under pebbles vs 2 on algae, and $3 \mathrm{~J}$. praehirsuta under pebbles vs 77 on algae. Ecological isolation can thus be estimated to $R I_{\text {eco,Brittany }}=98 \%$. Because this reproductive barrier is the first to occur in nature, all other barriers will have comparatively little effect in natural populations in this region. This is reflected in the values for absolute contributions $\left(A C_{i}\right.$ column in Table 2$)$.

However, as shown in Table 2 and Figure 3, no-choice intraspecific crosses in Brittany were more successful (probability of success $=0.9$ ) than interspecific crosses $(0.14$, Fisher's exact test $p<0.001)$. These results indicate strong sexual isolation $\left(R I_{1, \text { Brittany }}=0.73\right)$. That is, sexual isolation would reduce interspecific gene flow by about $70 \%$ in situations were individuals of the two species would meet, as in the case for instance when bold J. albifrons individuals venture on algae, or J. praehirsuta on pebbles.

By contrast, there was no ecological isolation in mixed J. albifrons / J. praehirsuta populations from Normandy (Table 2, data from Ribardière et al., 2017) and there we found sexual isolation to be half of that found in Brittany, although 95\% confidence intervals were overlapping (probability of success $=0.73$ vs. 0.33 for intra- and interspecific crosses, $R I_{1, \text { Normandy }}=0.37$, Fig. 3 ). Yet in this

360 region, sexual isolation was the first barrier to occur, and thus it effectively led to a strong reduction in interspecific gene flow $\left(A C_{1, \text { Normandy }}=R I_{1, \text { Normandy }}=0.37\right)$. This stands in contrast with the situation described above for Brittany where sexual isolation appeared stronger $\left(R I_{1, \text { Brittany }}=0.73\right)$ but had very little effect in nature $\left(A C_{1, \text { Britanny }}=0.015\right.$, Table 2$)$.

The time that a pair of individuals took to produce offspring (Fig. S1) did not enter calculations 365 of reproductive isolation following the framework of Sobel and Chen (2014), but it is interesting to note that intraspecific crosses produced offspring more quickly (41.2 days on average, $n=35$ ) than 
interspecific crosses (58.9 days, $n=7$, generalized linear model GLM with quasi-Poisson family $p=0.042$ ). The time needed to produce offspring seemed also more variable among interspecific crosses (Fig. S1). These observations further support sexual isolation in the studied populations (see discussion), but there were too few successful interspecific crosses to look at these data in each region separately.

Successful broods contained from 1 to 33 offspring (mean 7.9 ind.) and on average $79.8 \%$ of the offspring were still alive at day 35. Detailed data for intra- and interspecific crosses within each region are presented in Table 2. These data did not indicate any first-generation post-zygotic barrier 375 effect due to reduced F1 hybrid inviability in either region (Table 2). Accordingly, pooling data from our two regions, brood size (Fig. S2) did not differ significantly between intraspecific ( $n=35$ broods, mean 7.6 offspring per brood) and interspecific crosses ( $n=7$ broods, mean 9.3 offspring per brood, GLM quasi-Poisson family, $p=0.5)$. Although the few offspring produced by interspecific crosses gave little power for this test, we note that the point estimate for brood size was actually higher in

380 interspecific crosses. The same result was obtained for survival (Fig. S3, $n=265$ offspring from intraspecific crosses, $79 \%$ survival, $n=65$ offspring from interspecific crosses, $83 \%$ survival, GLM quasi-binomial family $p=0.6$ ).

\section{No-choice crosses across regions}

Experiments that crossed individuals from the same species but originating from distinct regions had a high success ( 28 out of 35 crosses produced offspring, Fig. 3 ) and this success was similar to that of intraspecific crosses within each region (Fisher's exact test $p=0.33$ ). Moreover, this high success was similar for J. albifrons pairs and J. praehirsuta pairs (respectively 15 out of 19 and 13 out of 16 crosses produced offspring, $p=1$ ). That is, there was no difference in success when a male

390 and a female came from the same $v s$ different regions, and this was true for each of the two species.

Focusing on the differences between intra- and interspecific crosses, all results obtained by crossing individuals from across two distinct regions were almost identical to the results presented 
above for crosses within a region. Briefly, intra-specific crosses were more successful ( $n=35$ crosses, probability of success $=0.8)$ than interspecific crosses $(n=35$, probability of success $=0.2$, Fisher's exact test $p<0.001$, Fig 3 ), delay to offspring production was shorter in intraspecific ( $n=28$ broods, 39.2 days on average) than interspecific crosses ( $n=7,65.3$ days, GLM quasi-Poisson $p=0.006$, Fig. S1), and there was no difference in brood size (intraspecific: $n=219$ offspring from 28 broods, 9.21 offspring per brood on average, interspecific: $n=68$ offspring from 7 broods, 11.7 offspring per brood, GLM quasi-Poisson $p=0.3$, Fig. S2) and survival at day 35, (intraspecific: $81 \%$ survival, interspecific: $79 \%$ survival, GLM quasi-binomial $p=0.8$, Fig. S3).

In summary, all differences in reproductive output from intra- versus inter-specific crosses were unaffected by the region of origin of the individuals.

\section{Results from the multiple-choice experimental population}

We could determine the reproduction patterns for 47 males (out of 51) and 22 females (out of $30)$, as detailed in the supplementary information. Out of 22 females, most (16) mated with a single male, while 5 had 2 mates and 1 had none (Fig. S4A). By contrast, the majority of males had no reproductive success ( 31 out of 47 ), while other males mated with 1 to 4 female partners. The distribution of reproductive success for males and females of each species is shown in Figs. S5 and S6.

A total of 26 male/female pairs produced offspring. As it turned out (Fig. 4), J. albifrons females reproduced only with J. albifrons males ( $n=18$ pairs), while J. praehirsuta females reproduced with the three types of males: J. praehirsuta males $(n=5)$, "hybrid" males, $(n=2)$, and J. albifrons males $(n=1)$. This distribution is not random (Fisher's exact test for independence between male and female

415 species composing these pairs $\mathrm{p}<0.001$ ) and leads to an estimate for sexual isolation between $J$. albifrons and J. praehirsuta equal to $R I_{1, \text { exp.pop. }}=0.92\left(\mathrm{Cl}_{95}[0.75 ; 1]\right)$, a number that can be directly compared with $R I_{1, \text { Normandy }}=0.37$ obtained from no-choice crosses. 
These results assume that all individuals had the same probability to mate. Rolan-Alvarez and Caballero's method based on the calculation of pair sexual isolation (PSI) is more conservative, since

420 it takes into account the effect of differences in mating success between individuals from each species (e.g. here J. albifrons individuals mated more frequently than others). Figure 4 shows the number of mating pairs of each possible type expected from random mating in absence of sexual isolation but taking into account the variation in mating frequencies. Estimates of PSI are given in Table S1. The global modified joint isolation index IPSI (Rolan-Alvarez \& Caballero, 2000) was equal to 0.46 , while pair-specific values were $I_{P S I}^{\text {albi/prae }}=0.92, I_{P S I}^{\text {albi } / \text { hybrid }}=1$, and $I_{P S I}^{\text {prae } / \text { hybrid }}=0.38$, indicating strong isolation between J. albifrons and J. praehirsuta, and lower isolation between J. praehirsuta and hybrids. Bootstrap-based tests performed in JMating for all PSI and $I_{\text {PSI }}$ estimates showed that only $I_{P S I}^{a l b i / p r a e}$ was statistically significant $(p=0.004)$.

Most of the variation in parent phenotypes (male secondary sexual traits) could be reduced to 430 two PCA axes (61.8\% and 18.3\% of the variation explained, Fig. 5A). Using PCA axis 1 to summarize male sexual traits in a univariate space, we see in Figure 5B that the mates preferred by J. albifrons females appear to coincide with the distribution of male sexual traits of J. albifrons, while J. praehirsuta females mated with males showing a wider range of trait values.

\section{Discussion}

Sexual isolation was effective both with and without ecological isolation

We found strong sexual isolation both in a context where ecological isolation is nearly complete $\left(R I_{\text {eco,Brittany }}=98 \%, R I_{1, \text { Brittany }}=73 \%\right)$ and in a context where there is no ecological isolation and individuals of the two species may hybridize $\left(R I_{\text {eco,Normandy }}=0, R I_{1, \text { Normandy }}=37 \%\right)$.

440 These RI values based on reproductive success in no-choice conditions suggest that sexual isolation is less effective when the two species co-occur in the same habitat (Normandy). However, the multiplechoice experiment showed that when the conditions allow females to escape males or choose amongst several males, then sexual isolation is in fact very efficient even in the hybridizing 
populations from Normandy $\left(R I_{1, \text { exp.pop. }}=92 \%\right)$. The exact same value was obtained using the joint

445 isolation index for J. albifrons and J. praehirsuta $\left(I_{P S I}^{\text {albi } / \text { prae }}=0.92\right)$, indicating that sexual isolation was effectively due to mate choice rather than differences in mating propensity between species.

Moreover, most of our no-choice crosses were monitored for a long time (5 to 196 days, median 22 days), meaning that females were confined with a given male in a tiny area for a long period, and thus our estimates probably give us a lower bound on sexual isolation. We conclude that 450 sexual isolation remains strong in populations where the two species share the same habitat, (despite hybridization and introgression, Ribardière, 2017; Ribardière et al., 2017) and thus sexual isolation in this system is largely independent of ecological isolation.

In addition, while males were identified as J. albifrons or J. praehirsuta based on phenotypes that are directly relevant to reproductive isolation, this was not the case for females, which were identified based on the phenotype of their brothers (see methods, Fig. 2, and supplementary information). Hence in all our experiments we had no direct information on the sexual phenotype of females (that is, preferences). This uncertainty on what really was a "J. albifrons" or a "J. praehirsuta" female in our experiments makes it all the more remarkable that sexual isolation was found to be strong, especially in the populations where the two species share the same habitat and hybridize. Three potential caveats must be considered. First, we took offspring production in intra- vs inter-specific crosses as an indicator of sexual isolation. This approach would be incorrect if intrinsic post-zygotic barriers were involved. Here brood size did not differ between intraspecific and interspecific crosses, and the abortion of an entire brood of embryos was never observed (oocytes and developing embryos are visible in the marsupium of females). Hence, conforming to what had 465 been reported previously (Solignac, 1978), females in the presence of a heterospecific male either produced no offspring because they did not mate, or produced a normal number of offspring. The success of crosses (presence vs absence of juveniles produced) was thus a good indicator of sexual isolation. 
Second, the multiple-choice population was not replicated. Although clear-cut patterns were observed, one cannot rule out that it was affected by an undetected experimental bias or that individuals originating from other populations would behave differently. For instance, the 81 individuals mixed in the experiment were produced in the lab from 17 pairs of parents, and each class of individuals (J. albifrons males, J. albifrons females, J. praehirsuta males, etc.) thus comprised 2 to 5 groups of siblings ( 1 to 9 siblings per family). Most notably, the fourteen J. albifrons females that survived the experiment and reproduced came from only two families, which could have biased the result if these 14 females were not representative of the range of female behaviour in natural populations. No-choice crosses have shown that this is not the case (J. albifrons females were very selective, both in intra-region and inter-region crosses), but repeating this experiment with more individuals, and perhaps with individuals from other regions where the two species have been found 480 in the same habitat, would be particularly interesting (e.g. in the UK, Naylor \& Haahtela, 1966; Mifsud, 2011; Ribardière, 2017).

\section{Did sexual isolation evolve independently of ecological contexts?}

J. praehirsuta individuals in Brittany vs. Normandy dwell on different habitats (pebbles vs.

485 brown algae). However, intraspecific crosses had exactly the same success (and the same delay to offspring production) whether or not males and females originated from the same region or different regions (Figs. 3 and S1), and this success was the same as that of J. albifrons pairs (within or across regions). Hence habitat differences did not generate any sign of sexual isolation between individuals originating from algae vs. rock populations in species J. praehirsuta. Sexual isolation was unaffected

490 by the habitat of origin and thus we conclude that it did not evolve through sexual selection mechanisms that are dependent of local ecological factors.

However, the ecological context could still have an effect on sexual isolation via two potential mechanisms. First, to suit our purpose of estimating reproductive isolation in different populations, all individuals were reared in identical, artificial lab conditions (see supplementary information) 
where all five species of the Jaera albifrons complex had been shown to have high fitness (Bocquet 1953; Solignac 1978). This means in particular that all individuals used in cross experiments were born and raised in the exact same conditions, regardless of their population of origin. Hence we cannot exclude that contrasted substrates (algae vs. rocks) could have some proximate effect on mate choice mechanisms, for instance through phenotypic plasticity in cuticular hydrocarbons or other chemical cues involved in sexual signalling (see e.g. Breithaupt \& Hardege, 2012, for a review of chemical cues in aquatic organisms; and Zhu et al., 2012 for an example involving sexual isolation). Such chemical signalling mechanisms have yet to be investigated in the Jaera albifrons complex, although we note that their effect on reproductive isolation would necessarily be somewhat limited because sexual isolation is already strong in uniform lab conditions. twice as strong in populations where the two species are ecologically separated $\left(R I_{1, \text { Brittany }}=73 \%\right.$, $\left.R I_{1, N o r m a n d y}=37 \%\right)$. One potential explanation is that mate choice is relaxed in introgressed populations, but only in situations where mate options are constrained (in agreement with our finding that sexual isolation was stronger in the multiple-choice experimental population $\left.R I_{1, \text { exp.pop. }}=92 \%\right)$. Variations in the relative abundance and spatial distribution of individuals in natural conditions may thus modulate the likelihood of interspecific mating. It is often argued that this could happen when dynamic habitats modulate the intensity of sexual isolation by limiting mate choice options, perhaps in some cases approaching no-choice conditions, if for example a female of species A finds herself isolated for some time with males of species B only. This could happen in

515 some of our populations where the quantity of sand covering pebbles and stones varies with climatic conditions across seasons and the density of individuals is low (e.g. Fig. S1 in supplementary material from Ribardière et al., 2017). Khaitov et al. (2007) also observed sharp variations in the relative frequencies of Jaera species in mixed populations that were presumably attributable to the destruction of nearby habitats. 
Sexual isolation is not strict, and it is asymmetric

Sexual isolation was strong, but it was not $100 \%$. Hence sexual isolation is not sufficient to prevent interspecific gene flow entirely on its own. As a result, when ecological isolation is lacking, hybridization is expected to happen occasionally.

Moreover, results from the multiple-choice experimental population showed sexual isolation to be asymmetric (Figs. 4 and 5). In this experiment, J. albifrons females mated exclusively with $J$. albifrons males while J. praehirsuta females mated with J. praehirsuta $(n=5)$, J. albifrons $(n=1)$ and F1 hybrid males $(n=2)$. Accordingly, pair sexual isolation indices for heterospecific pairs were smaller (indicating stronger isolation) when the female involved was J. albifrons rather than J. praehirsuta

530 (Table S1). Summarizing male sexual phenotypes using the first axis of a principal component analysis (Fig. 5), we found that the probability that a male mated with a J. albifrons female matched relatively well the density distribution of J. albifrons male sexual traits. By contrast, the probability that a male mated with a J. praehirsuta female was clearly less concordant to the density distribution of $J$. praehirsuta male sexual traits (Fig. 5B). This shows that females J. praehirsuta mated with our three 535 categories of males (J. praehirsuta, F1 hybrids, and J. albifrons) because they are less selective that J. albifrons females with regards to male sexual traits (illustrative of "type d" preference function in Fig. 5 from Ryan \& Rand, 1993).

This asymmetry is also confirmed by the no-choice experiments, where inter-specific crosses were systematically more successful with J. praehirsuta females. Over all interspecific crosses, 4 out of 36 were successful when the female was J. albifrons, while 10 out of 28 were successful when the female was J. praehirsuta (Fisher's exact test $p=0.036$, Fig. 6). Interestingly, the same result was obtained by M. Solignac with no-choice experiments using individuals from a population from France (Brittany) crossed with individuals from Germany (0\% success for German J. albifrons females crossed with French J. praehirsuta males vs 22 to $46 \%$ success for French J. praehirsuta females 545 crossed with German J. albifrons males, depending on the method of calculation, Solignac, 1978). 
The asymmetry in sexual isolation is thus observed in all conditions: large-scale allopatry (between countries, Solignac, 1978), smaller-scale allopatry (between regions, this study), sympatry with ecological isolation and no hybridization (Brittany, this study), and sympatry without ecological isolation and with introgressive hybridization (Normandy, this study). This is interesting because it suggests that the asymmetry has a general cause of ancestral origin and has not evolved in response to local conditions, in agreement with our previous conclusion that sexual isolation has not evolved following mechanisms that depend on local habitat conditions.

Why do J. albifrons and J. praehirsuta coexist in hybridizing populations? Individuals identified as J. albifrons in region Brittany (with ecological isolation) belong to the same biological species as individuals identified as J. albifrons in region Normandy (where there is no ecological isolation), and likewise for species J. praehirsuta. This was argued by taxonomists and evolutionary biologists based on the observation of secondary sexual traits (Bocquet, 1953; Prunus, 1968; Solignac, 1978) and confirmed in this study using cross experiments: conspecific crosses gave 560 the same results within and across regions (no reproductive isolation between regions).

However, we also know that reproductive isolation is not complete in populations without ecological isolation, where hybridization leads to introgression (Bocquet \& Solignac, 1969; Solignac, 1969a; 1978; Ribardière et al., 2017). This situation raises questions about the conditions of coexistence of the two species in spite of hybridization and ecological equivalence (e.g. Coyne \& Orr,

565 1998). Ribardière et al. (2017) discussed the peculiar nature of the hybridizing populations, emphasizing that they seem to receive no influx of individuals from pure parental populations, and that no fine-scale ecological differentiation was observed (the two species are repeatedly found to be intermingled in a number of different sites). The authors suggested sexual and post-zygotic isolation as two potential forces somehow acting to keep the species isolated. Here we found sexual 570 isolation to be effectively strong in hybridizing populations, but no support for first-generation intrinsic post-zygotic mechanisms $\left(A C_{2}\right.$ and $A C_{3}$ added to -0.04 and -0.06 in regions Brittany and 
Normandy, Table 2). Moreover, this result was confirmed by between-regions crosses showing similar brood size and offspring survival for intra- and interspecific crosses. We could not quantify intrinsic post-zygotic isolation from the multiple-choice experimental population because only one

575 heterospecific mating pair and two backcrosses (F1-hybrid fathers) produced offspring. Yet these broods showed no sign of reduced fitness in any way (brood size and offspring survival, data not shown). Post-zygotic barrier effects need to be investigated further (especially in later generations), but so far, sexual processes (mate choice and/or intra-sexual interactions) constitute the only force identified that could maintain the two species separated in spite of extensive introgression. This

580 alone is unusual, and the fact that the two species are found to coexist in different places and on the long term despite ecological equivalence poses another conundrum that deserves further investigations.

\section{Conclusion \& open questions}

In this study we looked at two closely related species that are reproductively isolated by ecological and sexual barriers, asking first if sexual isolation could maintain species integrity on its own or is only acting secondarily alongside ecological isolation, and second if sexual isolation may have evolved independently of local ecological context. We found that sexual isolation is a strong barrier that does not break down when ecological isolation is absent and most probably evolved independently of local ecological conditions. The tactile courtship of J. albifrons and J. praehirsuta therefore probably exemplifies a situation where the set of genes and traits involved in male phenotypes and female preferences have no simultaneous role in local adaptation to different habitats and are not constrained by natural selection (no environmental effect on sexual traits, courtship behaviour, transmission of sexual signals, or choosiness). Under these conditions one can

595 expect sexual isolation to be largely independent of ecological isolation, as observed for instance in some Chorthippus grasshoppers (Bridle et al., 2001; Bridle et al., 2002) and Laupala crickets (Mendelson \& Shaw, 2005) in which female mate choice is based on male calling songs. In some 
Drosophila species, laboratory lines reared in artificial conditions provide another example where mate choice based on male courtship songs and pheromones (reviewed in Coyne \& Orr, 1997) has no

600 obvious ecological component (although this will not be the case of all Drosophila species, see e.g. Stennett \& Etges, 1997; Etges, 2002). A few other potential examples have been reviewed by Svensson (2012). Will reproductive isolation be generally weaker in these conditions? Empirical examples reported in the literature show that reproductive isolation can be particularly strong when sexual isolation is inherently coupled with ecological isolation (Servedio et al., 2011). Whether this is

605 a general rule remains to be clarified.

Local ecological conditions could still affect the strength of sexual isolation if habitat dynamics modulate mate choice possibilities through stochastic effects on population densities. Whether such effects could constrain mate choice sufficiently to bypass sexual isolation and affect the likelihood of speciation completion remains an open question. More importantly, we found that reproductive

610 isolation was not complete without ecological isolation. Both J. albifrons and J. praehirsuta are found in variable ecological contexts along the shores of the temperate and cold waters on both sides of the North-Atlantic Ocean and nearby seas. Whether or not there is niche differentiation may influence the local coexistence and hybridization of these species.

Finally, the conditions of coexistence of these two species in hybridizing populations are 615 another open question. For that, further examination of post-zygotic barrier effects, fine-scale tests for cryptic habitat specialization, and interactions favouring density-dependence mechanisms (such as species-specific pathogen effects) may provide some answers.

\section{Acknowledgements}

We thank Carole Smadja for discussions and insightful comments on this article, and Sébastien Collin for the confocal laser scanning microscope images used in figures 1 and 5. Martine Maan, Emilio Rolán-Alvarez, Rui Faria, and three anonymous reviewers provided many useful comments on earlier versions of the manuscript. This work benefited from access to the Biogenouest genomic 
platform at Station Biologique de Roscoff and was funded by the French Agence Nationale de la

625 Recherche (grant ANR-13-JSV7-0001-01 to T.B.).

\section{Author contributions}

Conceptualization and methodology: AR and TB. Field sampling and species identification: AR, $E P, J C, C H, S L$ and TB. Crossing experiments and maintenance of the individuals in the laboratory: AR,

$630 \mathrm{EP}, \mathrm{JC}, \mathrm{CH}, \mathrm{SH}$, and TB. Genotyping and phenotyping: AR, EP, JC, CDT, CH and TB. Analyses and writing: AR, EP, and TB. Supervision, project administration and funding acquisition: TB.

\section{Conflict of interest disclosure}

The authors of this preprint declare that they have no financial conflict of interest with the

635 content of this article

\section{Data accessibility}

The data associated with this study are available on the Dryad digital repository at https://doi.org/10.5061/dryad.dv41ns1t8

640 


\section{References}

Arnold, S.J., Verrell, P.A. \& Tilley, S.G. 1996. The evolution of asymmetry in sexual isolation: A model and a test case. Evolution 50: 1024-1033.

Bailey, R.I., Saldamando-Benjumea, C.I., Tatsuta, H. \& Butlin, R.K. 2012. Habitat Association and Seasonality in a Mosaic and Bimodal Hybrid Zone between Chorthippus brunneus and C. jacobsi (Orthoptera: Acrididae). Plos One 7.

Bierne, N., Bonhomme, F. \& David, P. 2003. Habitat preference and the marine-speciation paradox. Proceedings of the Royal Society B-Biological Sciences 270: 1399-1406.

Bimova, B.V., Macholan, M., Baird, S.J.E., Munclinger, P., Dufkova, P., Laukaitis, C.M., Karn, R.C., Luzynski, K., Tucker, P.K. \& Pialek, J. 2011. Reinforcement selection acting on the European house mouse hybrid zone. Molecular Ecology 20: 2403-2424.

Bocquet, C. 1953. Recherches sur le polymorphisme naturel des Jaera Marina (Fabr.)(Isopodes Asellotes) : Essai de systématique évolutive, Centre national de la recherche scientifique.

Bocquet, C. \& Solignac, M. 1969. Etude morphologique des hybrides expérimentaux entre Jaera (albifrons) albifrons et Jaera (albifrons) praehirsuta (isopodes asellotes). Archives de zoologie expérimentale et générale 110: 435-452.

Boughman, J.W. 2001. Divergent sexual selection enhances reproductive isolation in sticklebacks. Nature 411: 944-948.

Boughman, J.W. 2002. How sensory drive can promote speciation. Trends in Ecology \& Evolution 17: 571-577.

Boughman, J.W. \& Svanback, R. 2017. Synergistic selection between ecological niche and mate preference primes diversification. Evolution 71: 6-22.

Breithaupt, T. \& Hardege, J.D. 2012. Pheromones mediating sex and dominance in aquatic animals. Chemical Ecology in Aquatic Systems: 39-56.

Bridle, J.R., Baird, S.J.E. \& Butlin, R.K. 2001. Spatial structure and habitat variation in a grasshopper hybrid zone. Evolution 55: 1832-1843. 
Bridle, J.R., Vass-De-Zomba, J. \& Butlin, R.K. 2002. Fine-scale ecological and genetic variation in a Chorthippus grasshopper hybrid zone. Ecological Entomology 27: 499-504.

Bridle, J.R., Saldamando, C.I., Koning, W. \& Butlin, R.K. 2006. Assortative preferences and discrimination by females against hybrid male song in the grasshoppers Chorthippus brunneus and Chorthippus jacobsi (Orthoptera : Acrididae). Journal of Evolutionary Biology 19: $1248-1256$.

Butlin, R.K. \& Smadja, C.M. 2018. Coupling, Reinforcement, and Speciation. The American Naturalist 191: $155-172$.

Carvajal-Rodriguez, A. \& Rolan-Alvarez, E. 2006. JMATING: a software for the analysis of sexual selection and sexual isolation effects from mating frequency data. Bmc Evolutionary Biology 6.

Coyne, J.A. \& Orr, H.A. 1997. "Patterns of speciation in Drosophila" revisited. Evolution 51: 295-303. Coyne, J.A. \& Orr, H.A. 1998. The evolutionary genetics of speciation. Philosophical Transactions of the Royal Society of London Series B-Biological Sciences 353: 287-305.

Coyne, J.A. \& Orr, H.A. 2004. Speciation. Sinauer associates, Sunderland.

Coyne, J.A., Elwyn, S. \& Rolan-Alvarez, E.L. 2005. Impact of experimental design on Drosophila sexual isolation studies: Direct effects and comparison to field hybridization data. Evolution 59: 2588-2601.

Culumber, Z.W., Fisher, H.S., Tobler, M., Mateos, M., Barber, P.H., Sorenson, M.D. \& Rosenthal, G.G. 2011. Replicated hybrid zones of Xiphophorus swordtails along an elevational gradient. Molecular Ecology 20: 342-356.

Etges, W.J. 2002. Divergence in mate choice systems: does evolution play by rules? Genetica 116: 151-166.

Harrison, R.G. \& Rand, D.M. 1989. Mosaic hybrid zones and the nature of species boundaries. In: Speciation and its consequences (D. Otte \& J. A. Endler, eds), pp. 111-133. Sinauer Associates, Inc. 
Harrison, R.G. \& Larson, E.L. 2016. Heterogeneous genome divergence, differential introgression, and the origin and structure of hybrid zones. Molecular Ecology 25: 2454-2466.

Hasselman, D.J., Argo, E.E., Mcbride, M.C., Bentzen, P., Schultz, T.F., Perez-Umphrey, A.A. \& Palkovacs, E.P. 2014. Human disturbance causes the formation of a hybrid swarm between two naturally sympatric fish species. Molecular Ecology 23: 1137-1152.

Hohenlohe, P.A. \& Arnold, S.J. 2010. Dimensionality of mate choice, sexual isolation, and speciation. Proceedings of the National Academy of Sciences of the United States of America 107: 1658316588.

Jiggins, C.D., Naisbit, R.E., Coe, R.L. \& Mallet, J. 2001. Reproductive isolation caused by colour pattern mimicry. Nature 411: 302-305.

Jones, M. 1972. Effects of salinity on the survival of the Jaera albifrons Leach group of species (Crustacea: Isopoda). Journal of Experimental Marine Biology and Ecology 9: 231-237.

Jones, M.B. \& Fordy, M.R. 1971. Stereoscan Electron Microscope Study of Male Reproductive Characters in Jaera-Albifrons Group of Species (Crustacea-Isopoda). Marine Biology 10: 265$\&$.

Jones, O.R. \& Wang, J.L. 2010. COLONY: a program for parentage and sibship inference from multilocus genotype data. Molecular Ecology Resources 10: 551-555.

Khaitov, V.M., Kuzmin, A.A. \& Terovskaya, E.V. 2007. Morphological differences between females of different Jaera species (Crustacea : Asellota : Isopoda) in the White Sea: a possible solution to an old problem. Marine Biology 150: 1205-1214.

Lécher, P. \& Prunus, G. 1971. Caryologie et taxinomie de Jaera albifrons (crustacé, isopode), populations des côtes Bretonnes. Archives de Zoologie expérimentale et générale 112: 715730.

Maan, M.E. \& Seehausen, O. 2011. Ecology, sexual selection and speciation. Ecology Letters 14: 591602. 
McNett, G.D. \& Cocroft, R.B. 2008. Host shifts favor vibrational signal divergence in Enchenopa binotata treehoppers. Behavioral Ecology 19: 650-656.

Mendelson, T.C. \& Shaw, K.L. 2005. Sexual behaviour: Rapid speciation in an arthropod. Nature 433: 375-376.

Merrell, D.J. 1950. Measurement of Sexual Isolation and Selective Mating. Evolution 4: 326-331.

Mifsud, D.V. 2011. The genetic basis of speciation in the Jaera albifrons species group of intertidal isopods, University of Aberdeen. PhD: 201.

Naylor, E. \& Haahtela, I. 1966. Habitat Preferences and Interspersion of Species within Superspecies Jaera Albifrons Leach (Crustacea . Isopoda). Journal of Animal Ecology 35: 209-\&.

Naylor, E. \& Haahtela, I. 1967. Quantitative ecological distribution of the Jaera albifrons group of species in the Baltic. Ophelia 4: 19-27.

Nosil, P., Crespi, B.J. \& Sandoval, C.P. 2002. Host-plant adaptation drives the parallel evolution of reproductive isolation. Nature 417: 440-443.

Nosil, P. 2012. Ecological Speciation. Ecological Speciation: 1-280.

Perez-Figueroa, A., Caballero, A. \& Rolan-Alvarez, E. 2005. Comparing the estimation properties of different statistics for measuring sexual isolation from mating frequencies. Biological Journal of the Linnean Society 85: 307-318.

Prunus, G. 1968. Etude de systématique des populations chez l'isopode Jaera (albifrons) albifrons Forsman. Archives de zoologie expérimentale et générale 109: 643-702.

R Core Team 2017. R: A language and environment for statistical computing, R Foundation for Statistical Computing. Vienna, Austria. URL http://www.R-project.org.

Ribardière, A., Broquet, T. \& Daguin-Thiébaut, C. 2015. Microsatellite markers for the Jaera albifrons species complex (marine isopods). BMC Research Notes 8: 632.

Ribardière, A. 2017. Isolement reproductif et architecture génomique de la différenciation chez deux espèces du complexe Jaera albifrons (isopodes marins) - Etude de populations mixtes 
présentant des niveaux d'isolement interspécifique contrastés, Pierre \& Marie Curie University. PhD: 276.

Ribardière, A., Daguin-Thiébaut, C., Houbin, C., Coudret, J., Broudin, C., Timsit, O. \& Broquet, T. 2017. Geographically distinct patterns of reproductive isolation and hybridization in two sympatric species of the Jaera albifrons complex (marine isopods). Ecology and Evolution 7: 5352-5365.

Ritchie, M.G. 2007. Sexual selection and speciation. Annual Review of Ecology Evolution and Systematics 38: 79-102.

Rolan-Alvarez, E. \& Caballero, M. 2000. Estimating sexual selection and sexual isolation effects from mating frequencies. Evolution 54: 30-36.

Rougemont, Q., Gaigher, A., Lasne, E., Cote, J., Coke, M., Besnard, A.L., Launey, S. \& Evanno, G. 2015. Low reproductive isolation and highly variable levels of gene flow reveal limited progress towards speciation between European river and brook lampreys. Journal of Evolutionary Biology 28: 2248-2263.

Ryan, M.J. \& Rand, A.S. 1993. Species recognition and sexual selection as a unitary problem in animal communication. Evolution 47: 647-657.

Safran, R.J., Scordato, E.S.C., Symes, L.B., Rodriguez, R.L. \& Mendelson, T.C. 2013. Contributions of natural and sexual selection to the evolution of premating reproductive isolation: a research agenda. Trends in Ecology \& Evolution 28: 643-650.

Seehausen, O., Terai, Y., Magalhaes, I.S., Carleton, K.L., Mrosso, H.D.J., Miyagi, R., van der Sluijs, I., Schneider, M.V., Maan, M.E., Tachida, H., Imai, H. \& Okada, N. 2008. Speciation through sensory drive in cichlid fish. Nature 455: 620-U623.

Seehausen, O. 2009. Progressive levels of trait divergence along a 'speciation transect' in the lake Victoria cichlid fish Pundamilia. In: Speciation and patterns of diversity (R. Butlin, J. Bridle \& D. Schluter, eds), pp. 155-176. Cambridge University Press.

Servedio, M.R., Van Doorn, G.S., Kopp, M., Frame, A.M. \& Nosil, P. 2011. Magic traits in speciation: 'magic' but not rare? Trends in Ecology \& Evolution 26: 389-397. 
Servedio, M.R. \& Boughman, J.W. 2017. The Role of Sexual Selection in Local Adaptation and Speciation. Annual Review of Ecology, Evolution, and Systematics 48: 85-109.

Smadja, C., Catalan, J. \& Ganem, G. 2004. Strong premating divergence in a unimodal hybrid zone between two subspecies of the house mouse. Journal of Evolutionary Biology 17: 165-176.

Smadja, C. \& Ganem, G. 2005. Asymmetrical reproductive character displacement in the house mouse. Journal of Evolutionary Biology 18: 1485-1493.

Sobel, J.M. \& Chen, G.F. 2014. Unification of Methods for Estimating the Strength of Reproductive Isolation. Evolution 68: 1511-1522.

Solignac, M. 1969a. Hybridation introgressive dans la population complexe des Jaera albifrons de Luc-sur-Mer. Archives de zoologie expérimentale et générale 110: 629.

Solignac, M. 1969b. Contiguous Distributions Sympatry and Natural Hybridization in a Super-Species Jaera Albifrons Leach (Isopods Asellidae). Comptes Rendus Hebdomadaires Des Seances De L Academie Des Sciences Serie D 268: 1610-\&.

Solignac, M. 1976. Demographic aspects of interspecific hybridization - A study of the Jaera albifrons species complex (Crustacea, Isopoda, Asellota). Oecologia 26: 33-52.

Solignac, M. 1978. Nature, déterminisme et origine des mécanismes d'isolement dans le complexe Jaera albifrons (Isopodes, Asellotes). Phd Thesis., PhD thesis.

Solignac, M. 1979. Experimental-Analysis and Variability of Interspecific Hybridization in the Species Complex Jaera-Albifrons (Crustacea, Isopoda). Archives De Zoologie Experimentale Et Generale 120: 353-378.

Solignac, M. 1981. Isolating mechanisms and modalities of speciation in the Jaera albifrons species complex (Crustacea, Isopoda). Systematic Zoology 30: 387-405.

Staiger, H. \& Bocquet, C. 1956. Les chromosomes de la super-espèce Jaera marina (F.) et de quelques autres Janiridae (Isopodes Asellotes). Bull. Biol. Fr. Belg 90: 1-32.

Stennett, M.D. \& Etges, W.J. 1997. Premating isolation is determined by larval rearing substrates in cactophilic Drosophila mojavensis. III. Epicuticular hydrocarbon variation is determined by 
use of different host plants in Drosophila mojavensis and Drosophila arizonae. Journal of Chemical Ecology 23: 2803-2824.

Svensson, E.I. 2012. Non-ecological speciation, niche conservatism and thermal adaptation: how are they connected? Organisms Diversity \& Evolution 12: 229-240.

Taylor, E.B., Boughman, J.W., Groenenboom, M., Sniatynski, M., Schluter, D. \& Gow, J.L. 2006. Speciation in reverse: morphological and genetic evidence of the collapse of a three-spined stickleback (Gasterosteus aculeatus) species pair. Molecular Ecology 15: 343-355.

Veuille, M. 1978. Biology of Reproduction in Jaera .1. Structure and Functionment of Males Copulatory Appendages. Cahiers De Biologie Marine 19: 299-308.

Zhu, J., Zhang, D. \& Lin, J.D. 2012. Asymmetric Mating Isolation between Two Caridean Shrimp: Lysmata Wurdemanni and Lysmata Boggessi. Journal of Shellfish Research 31: 195-199. 
Table 1 - Number of experimental "no-choice" crosses performed in order to estimate reproductive isolation

between marine isopods J. albifrons and J. praehirsuta in two French regions where they are ecologically isolated

(Brittany) or not (Normandy). Intra- and interspecific crosses were performed using males and females from the same region (intra-region) and different regions (inter-region). Inter-region crosses involved either females from Brittany (F. Britt) crossed to males from Normandy (M. Norm) or the opposite (F. Norm crossed to M. Britt).

\begin{tabular}{|c|c|c|c|c|c|c|}
\hline \multirow[t]{2}{*}{ Cross type } & \multirow[t]{2}{*}{ Female } & \multirow[t]{2}{*}{ Male } & \multicolumn{2}{|c|}{ Intra-region } & \multicolumn{2}{|l|}{ Inter-region } \\
\hline & & & Brittany & Normandy & F. Britt. x M. Norm. & F. Norm. x M. Britt. \\
\hline \multicolumn{7}{|c|}{ Intraspecific } \\
\hline & J. albifrons & J. albifrons & 17 & 6 & 10 & 10 \\
\hline & J. praehirsuta & J. praehirsuta & 6 & 17 & 10 & 10 \\
\hline \multicolumn{7}{|c|}{ Interspecific } \\
\hline & J. albifrons & J. praehirsuta & 10 & 10 & 10 & 10 \\
\hline & J. praehirsuta & J. albifrons & 7 & 7 & 10 & 10 \\
\hline
\end{tabular}


Table 2 - Components of reproductive isolation between marine isopods Jaera albifrons and J. praehirsuta in two regions with contrasting levels of isolation. Reproductive isolation (RI) was calculated following Sobel \& Chen (2014). Bootstrap confidence intervals $\left(\mathrm{Cl}_{95}\right)$ based on 10000 resampling of observed data are given whenever sample sizes were not too small (e.g. sample sizes for survival of interspecific offspring in Brittany were particularly small since interspecific crosses were rarely successful). RI gives the

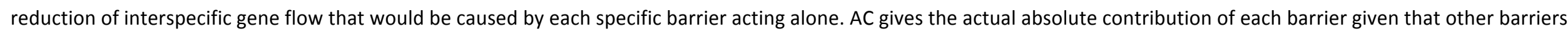
are acting earlier in life cycle. The sum of AC over all barriers is equal to the total strength of reproductive isolation. Sexual isolation contains a strong behavioural component, but could also include a (so far untested) gametic component. RI due to F1 hybrid inviability is based on brood size (number of offspring produced by a mother after intramarsupial development) and survival of these offspring after 35 days.

\begin{tabular}{|c|c|c|c|c|c|c|c|c|c|c|}
\hline \multirow[t]{2}{*}{ Barrier } & \multirow[t]{2}{*}{ Notation } & \multirow[t]{2}{*}{ Parameter } & \multicolumn{4}{|l|}{ Brittany } & \multicolumn{4}{|l|}{ Normandy } \\
\hline & & & Data & & $\mathrm{RI}\left[\mathrm{Cl}_{95}\right]$ & $A C$ & Data & & $\mathrm{RI}\left[\mathrm{Cl}_{95}\right]$ & $A C$ \\
\hline $\begin{array}{l}\text { Ecological } \\
\text { isolation }\end{array}$ & $R I_{\text {eco }}$ & $\begin{array}{l}\text { Probability of } \\
\text { heterospecific } \\
\text { encounter }\end{array}$ & $\begin{array}{l}5 / 222 \text { ind. in } \\
\text { shared habitat }\end{array}$ & $\begin{array}{l}217 / 222 \text { ind. in } \\
\text { unshared habitat }\end{array}$ & $\begin{array}{l}0.98 \\
{[0.955 ; 0.995]}\end{array}$ & 0.977 & $\begin{array}{l}80 / 80 \text { ind. in } \\
\text { shared habitat }\end{array}$ & $\begin{array}{l}0 / 80 \text { ind. in } \\
\text { unshared habitat }\end{array}$ & 0.00 & 0.00 \\
\hline $\begin{array}{l}\text { Sexual } \\
\text { isolation }\end{array}$ & $R I_{1}$ & $\begin{array}{l}\text { Proportion of } \\
\text { successful crosses }\end{array}$ & $\begin{array}{l}\text { 19/21 successful } \\
\text { intrasp. crosses }\end{array}$ & $\begin{array}{l}2 / 14 \text { successful } \\
\text { intersp. crosses }\end{array}$ & $\begin{array}{l}0.73 \\
{[0.45 ; 1]}\end{array}$ & 0.015 & $\begin{array}{l}\text { 16/22 successful } \\
\text { intrasp. crosses }\end{array}$ & $\begin{array}{l}5 / 15 \text { successful } \\
\text { intersp. crosses }\end{array}$ & $\begin{array}{l}0.37 \\
{[0.06 ; 0.73]}\end{array}$ & 0.37 \\
\hline \multirow[t]{2}{*}{$\begin{array}{l}\text { F1 hybrid } \\
\text { inviability }\end{array}$} & $R I_{2}$ & $\begin{array}{l}\text { Number of offspring } \\
\text { released per brood }\end{array}$ & $\begin{array}{l}6.2 \text { ind. ( } n=19 \\
\text { intrasp. broods) }\end{array}$ & $\begin{array}{l}5.5 \text { ind. ( } n=2 \\
\text { intersp. broods) }\end{array}$ & 0.06 & 0.001 & $\begin{array}{l}9.3 \text { ind. ( } n=16 \\
\text { intrasp. broods) }\end{array}$ & $\begin{array}{l}10.8 \text { ind. ( } n=5 \\
\text { intersp. broods) }\end{array}$ & -0.08 & -0.07 \\
\hline & $R I_{3}$ & $\begin{array}{l}\text { Survival probability } \\
\text { at } 35 \text { days }\end{array}$ & $\begin{array}{l}0.74 \text { ( } n=117 \\
\text { intrasp. offsp.) }\end{array}$ & $\begin{array}{l}0.91(n=11 \\
\text { intersp. offsp.) }\end{array}$ & -0.10 & -0.001 & $\begin{array}{l}0.83 \text { ( } n=148 \\
\text { intrasp. offsp.) }\end{array}$ & $\begin{array}{l}0.81 \text { ( } n=54 \\
\text { intersp. offsp.) }\end{array}$ & $\begin{array}{l}0.01 \\
{[-0.06} \\
0.09]\end{array}$ & 0.01 \\
\hline $\begin{array}{l}\text { Total } \\
\text { reproductive } \\
\text { isolation }\end{array}$ & $R I_{\text {tot }}$ & & & & 0.99 & 0.99 & & & 0.31 & 0.31 \\
\hline
\end{tabular}


Figure 1
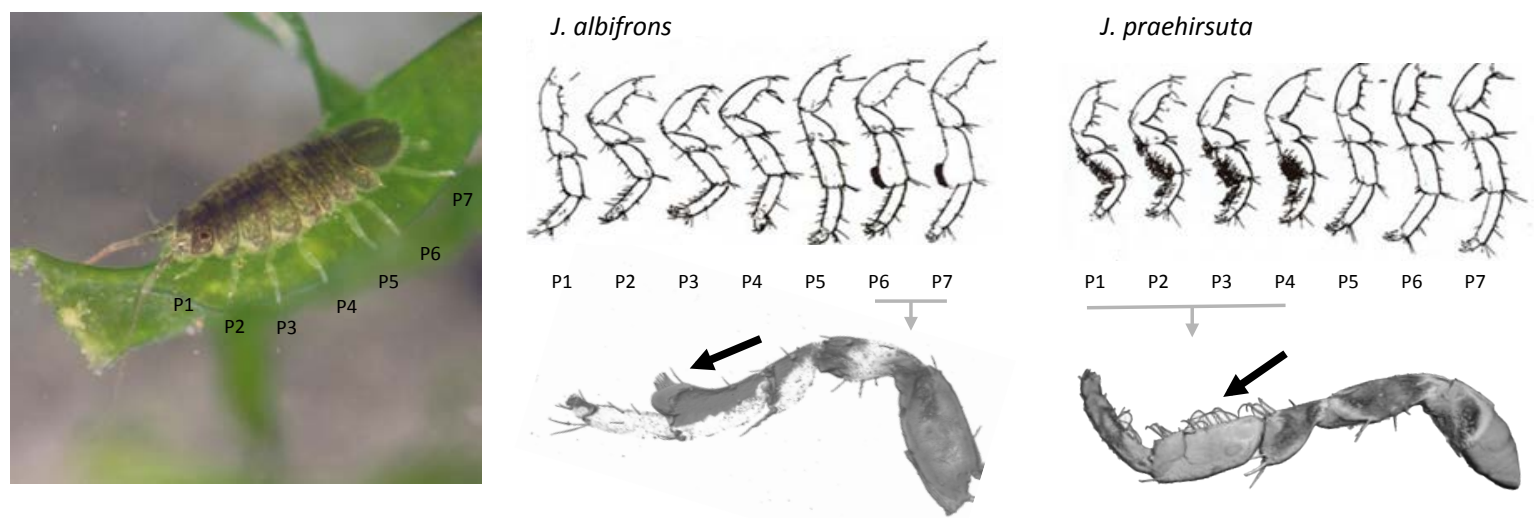

Figure 1

Sexual traits used for tactile courtship by male Jaera albifrons and J. praehirsuta. In male J. albifrons, the second segment (carpus) of peraeopods 6 and 7 extends as a lobe bearing a patch of setae (indicated by the black arrow on the left). Male J. praehirsuta instead have curved setae distributed on the first three segments (propus, carpus, merus) of peraeopods 1-4 (right black arrow), and one or two spines on the carpus of peraeopods 6 and 7. The photo on the left shows a $4 \mathrm{~mm}$-long adult female (photo credit to Guillaume Evanno \& Thomas Broquet). The drawings are reproduced from Solignac (1981) with authorization. After fluorescent labelling of dissected appendices, close-up pictures were obtained with a confocal laser scanning microscope and processed using software Fiji and IMARIS (photo credit to Sébastien Colin). 
Figure 2

\section{Preliminary steps}

1 - Females sampled from natural populations

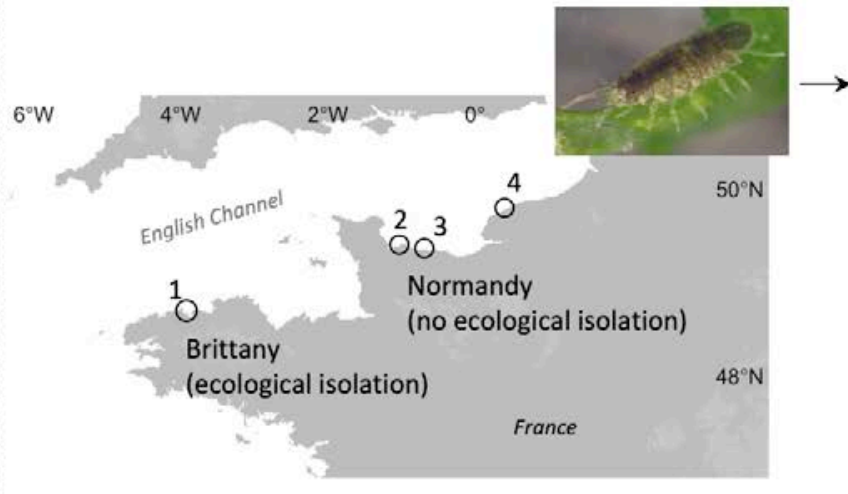

Species identification using secondary sexual traits
2 - Females maintained in the laboratory until they produce offspring
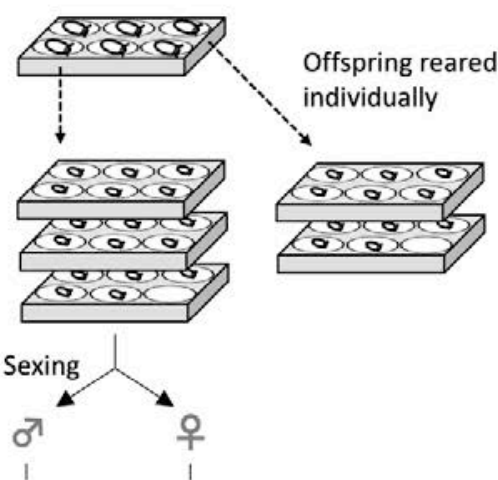

Species identification based on brothers' phenotypes

No-choice experiments:

controlled intra-specific and inter-specific crosses

$10^{\pi}$

J. albifrons or J. praehirsuta

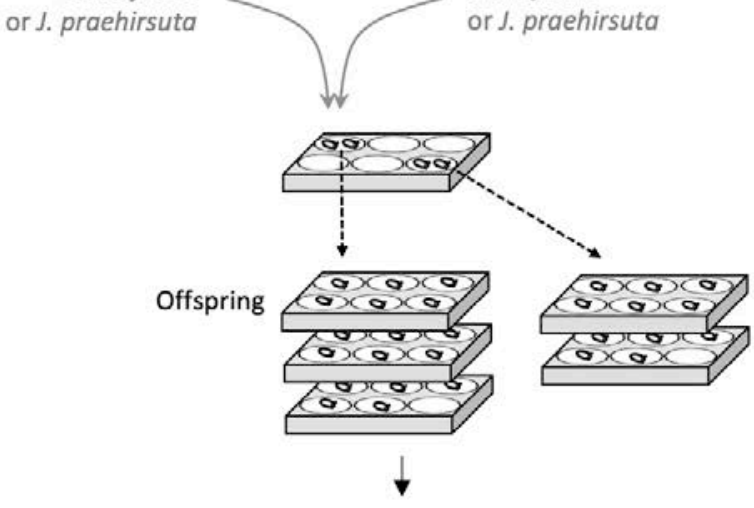

Cross success

Delay to offspring production

Brood size

35-days survival

Reproductive isolation estimates

\section{Free-choice experiment}

$510^{2}$

30 우

$17 \mathrm{~J}$. albifrons

$17 \mathrm{~J}$. praehirsuta

17 F1 hybrids

$15 \mathrm{~J}$. albifrons

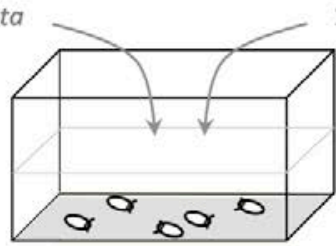

$15 \mathrm{~J}$. praehirsuto

$\downarrow$ Females are isolated

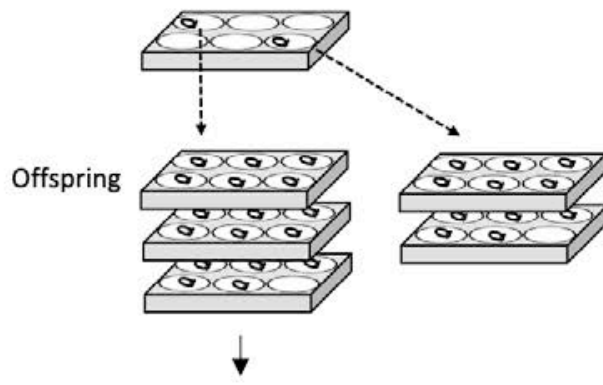

Genotyping and parentage assignment

Reproductive isolation estimates

Figure 2 - Outline of experimental protocols. The upper panel presents the preliminary steps that were taken to obtain virgin males and females of each species, which could then be used in 
controlled experiments. Adult females were sampled from natural populations as shown on the map. We knew from previous genetic analyses that local sympatric populations of $J$. albifrons and $J$.

praehirsuta were reproductively isolated (region Brittany) or not (introgressive hybridization, region Normandy). Adult females were kept in the laboratory until they produced offspring that were then raised until the male offspring could be identified. Virgin individuals born in the lab were then chosen to be used in no-choice cross experiments. Individuals born and reared in the lab following these nochoice experiments were then used in a multiple-choice experimental population. 
Figure 3

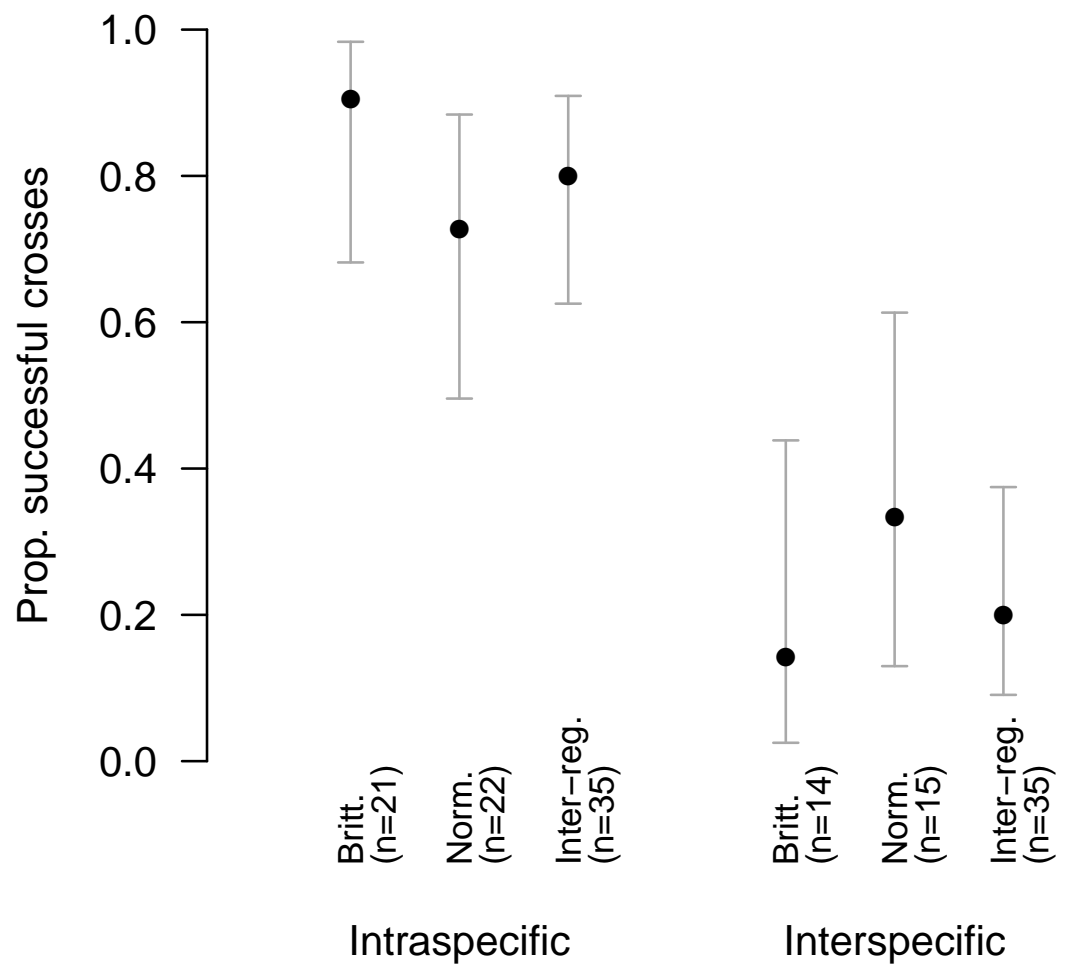

Figure 3 - Proportion of successful crosses in no-choice experiments involving intraspecific crosses (either Jaera albifrons or J. praehirsuta) and inter-specific crosses. The male and female of a given cross could come from the same region (Brittany or Normandy, see text) or from a different region (inter-reg. crosses). The sample sizes (number of experimental crosses) are given within brackets, and the bars give $95 \%$ confidence intervals around each observed proportion. A cross was successful if it produced at least one offspring. Interspecific crosses were consistently less successful than intraspecific ones, pointing towards sexual isolation between J. albifrons and J. praehirsuta. 
Figure 4

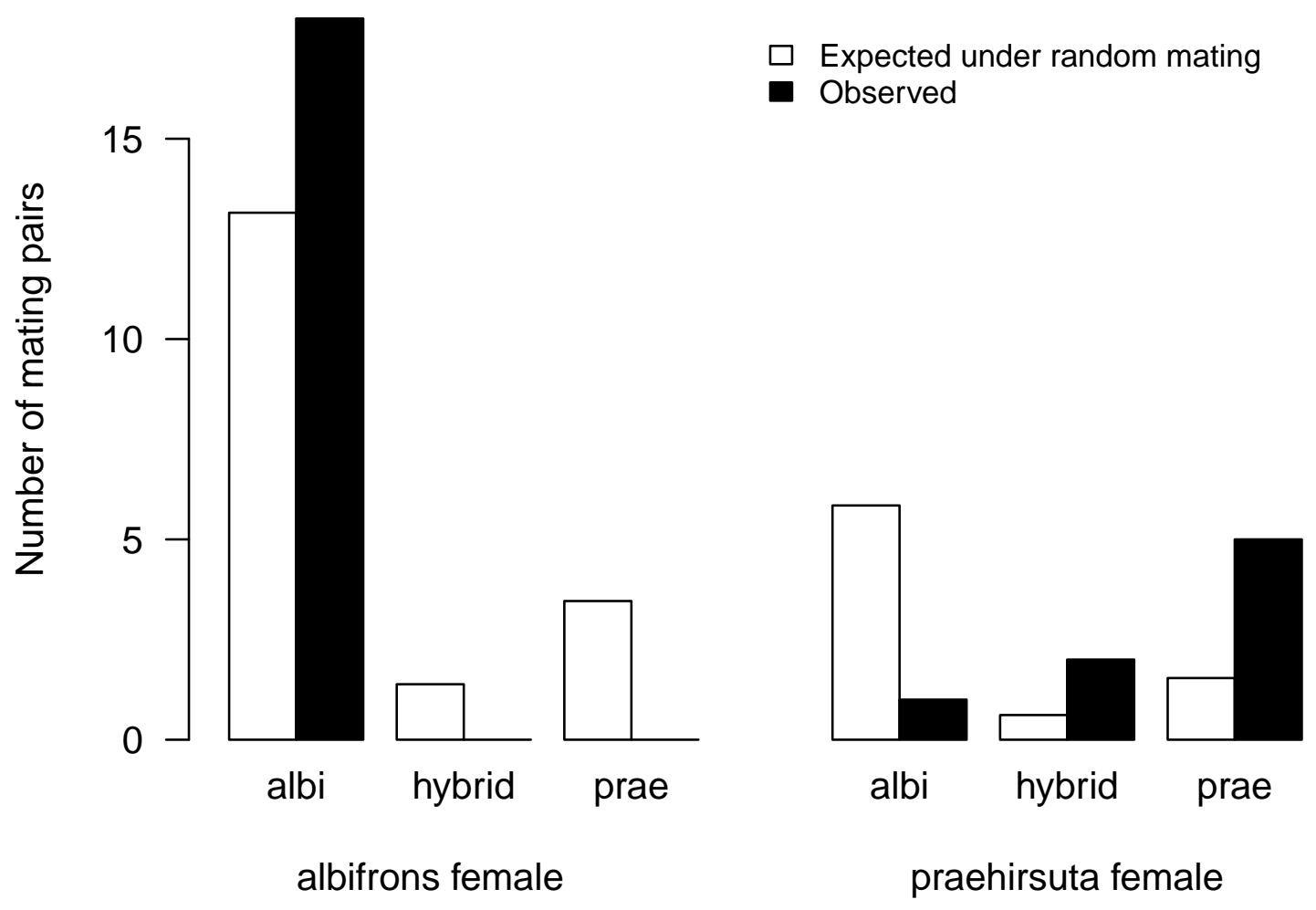

Figure 4

Number of mating pairs of each possible type expected from random mating in absence of sexual isolation (white bars) and observed from an experimental population (black bars). The expected numbers take into account not only the number of males and females of each type that entered the experiment but also their propensity to mate (see text). We see that J. albifrons females mated successfully only with J. albifrons males, while J. praehirsuta females produced offspring with males of the three different types, although not in equal proportions. These results point to strong but imperfect, asymmetric sexual isolation. 
Figure 5

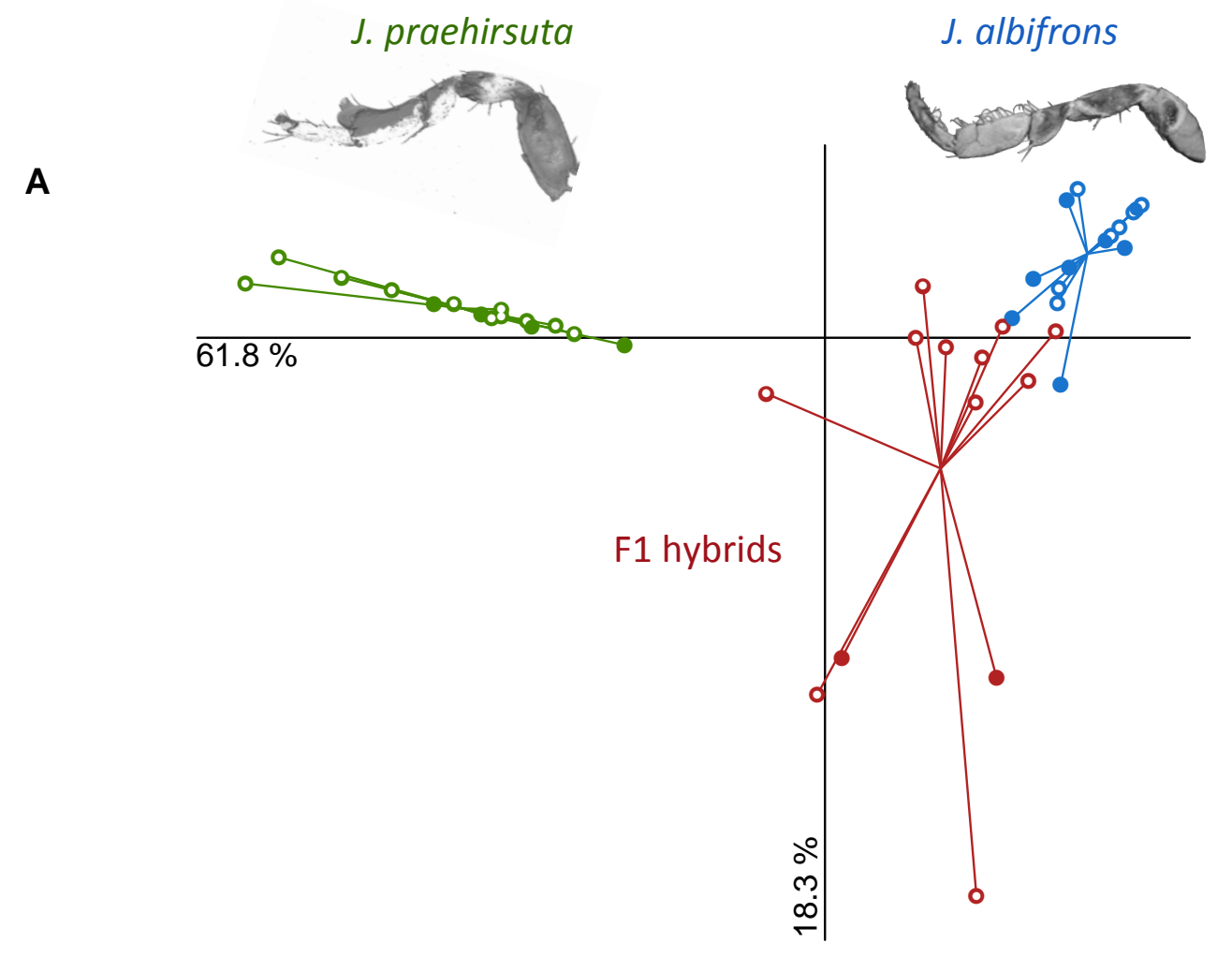

B

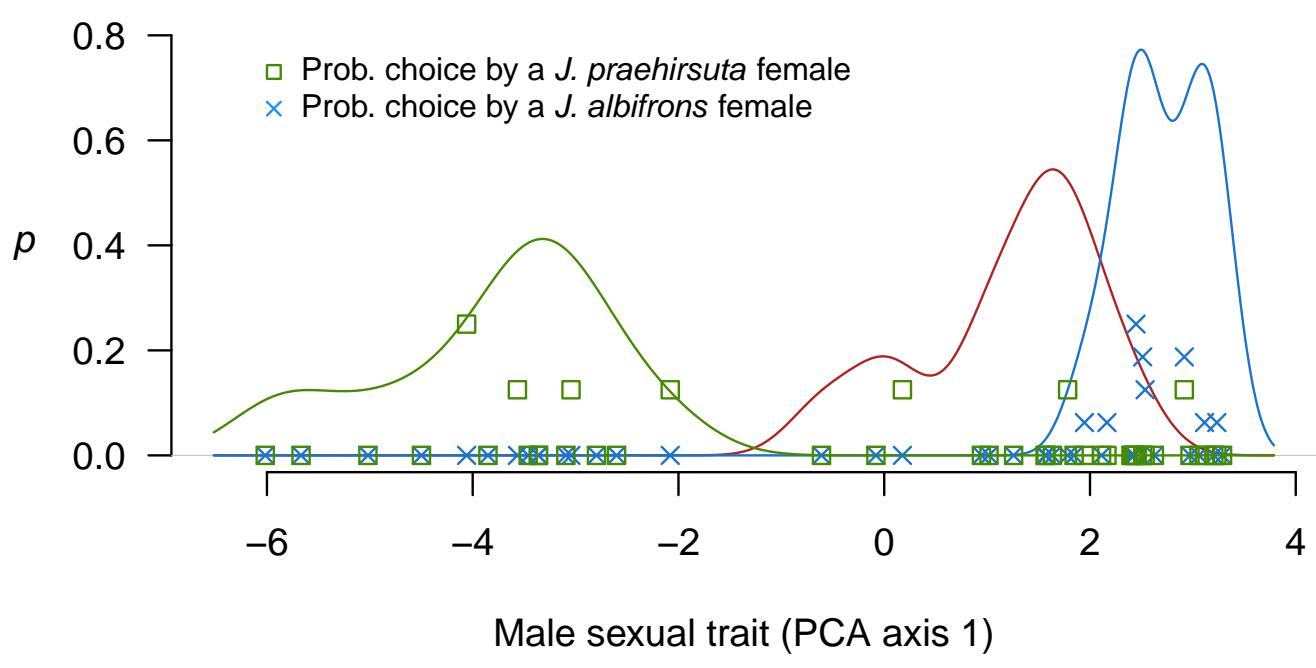

Figure 5

Asymmetric sexual isolation between Jaera albifrons and J. praehirsuta. Panel A) shows the first two components of a principal component analysis of male phenotypes (potential parents in the multiple-choice experimental population) grouped by types. We see that individuals of the albifrons or praehirsuta types are phenotypically differentiated, while individuals of the hybrid type (i.e. 
produced by an "interspecific" cross) show more phenotypic variability, including phenotypes indistinguishable from the parental morphs. In this PCA plot, empty circles represent the males that did not sire any offspring, while solid dots show the males that successfully reproduced. In panel B), the solid curves show the density distribution of male sexual trait values in univariate space (PCA axis 1 only). The probability that a female mated with a male showing a particular sexual trait value is shown by green squares (J. praehirsuta females) and blue crosses (J. albifrons females). The preferred mates of $J$. albifrons females coincide with the distribution of $J$. albifrons male sexual trait. By contrast, this concordance is much relaxed for J. praehirsuta females, which mated with males showing a wide range of trait values. 
Figure 6

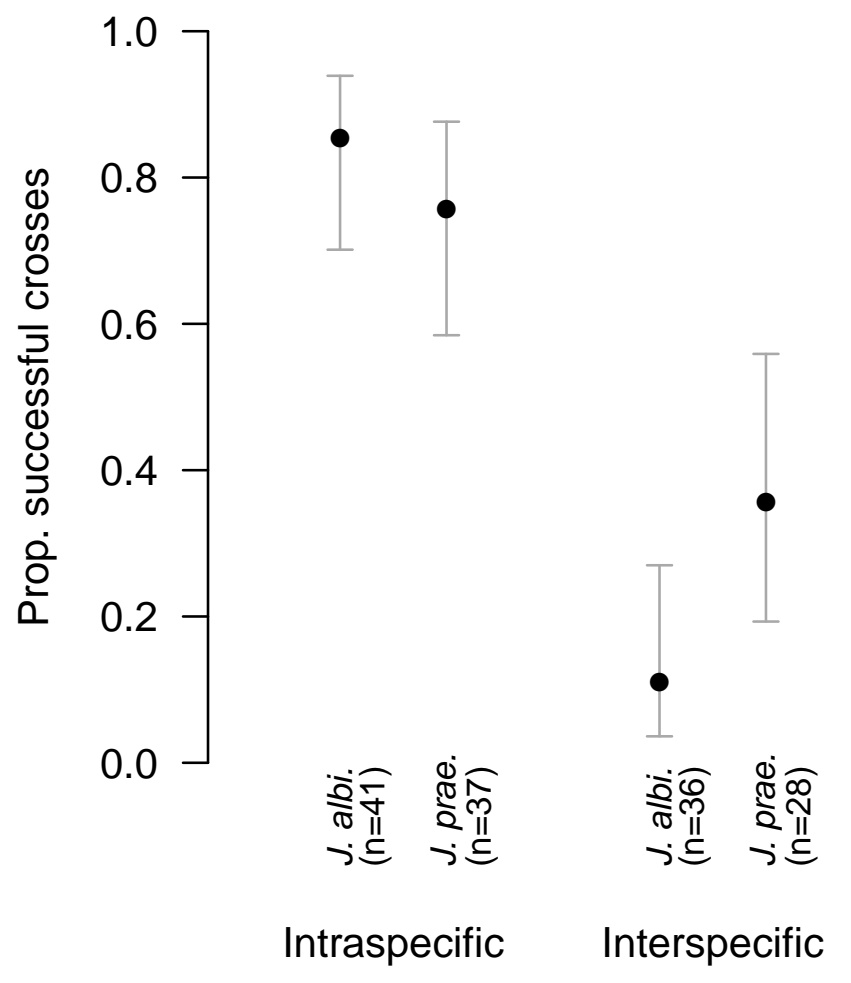

Figure 6 - Proportion of successful intra- and interspecific crosses in no-choice experiments involving either J. albifrons or J. praehirsuta females. The sample sizes (number of experimental crosses) are given within brackets, and the bars give $95 \%$ confidence intervals around each observed proportion. A cross was successful if it produced at least one offspring. Sexual isolation between species is stronger in one direction (J. albifrons female). 